\title{
A EDUCAÇÃO BÁSICA CEARENSE EM ÉPOCA DE PANDEMIA DE CORONAVÍRUS(COVID-19): PERSPECTIVAS E DESAFIOS NO CENÁRIO EDUCACIONAL BRASILEIRO
}

\section{The Basic Education in Ceará during Coronavirus pandemic (COVID-19): perspectives and challenges in the Brazilian educational scenario}

Samiles Vasconcelos Cruz Benedito ${ }^{1}$ Pedro Julio de Castro Filho

\begin{abstract}
Resumo: Este trabalho objetiva investigar as medidas adotadas na educação básica brasileira para melhor gerir as ações de enfrentamento ao Covid-19, traçando um paralelo com a realidade cearense. Caracteriza-se como uma pesquisa qualitativa, baseada no método descritivo-explicativo. Realizou-se uma busca na base de dados da Scielo (Scientific Electronic Library Online), em revistas científicas online da área de Educação e Comunicação, reportagens e outros documentos produzidos sobre o tema. Percebeu-se que a adoção das aulas remotas como estratégia de ensino durante a pandemia, trouxe consigo uma gama de desafios, além dos já existentes, como a infraestrutura inadequada e o despreparo docente frente ao uso da tecnologia em sala de aula. Cerca de $88 \%$ dos professores nunca tinham ministrado aulas virtuais antes da pandemia, o que dificultou ainda mais o processo de adaptação a esse novo cenário.
\end{abstract}

Palavras-chave: mídia, educação, tecnologia, ensino remoto.

\begin{abstract}
This article aims to investigate the measures adopted in the Brazilian basic education to achieve a better management of the actions to confront the Covid-19, drawing a parallel with the reality of Ceará. Characterized as a qualitative research, based on the descriptive-explanatory method. It was conducted a search in the SciELO (Scientific Electronic Library Online) database, in online scientific journals in the area of Education and Communication, reports and other documents produced about the subject. It was noticed that the adoption of remote classes as a teaching strategy during the pandemic brought with it a range of challenges, in addition to those already faced, such as inadequate infrastructure and the unpreparedness of teachers concerning the use of technology in the classroom. Almost $88 \%$ of teachers had never conducted virtual classes before the pandemic, which made it even more difficult to adapt to this new scenario.
\end{abstract}

Key-words: media, education, technology, remote education.

\footnotetext{
1 Especialista em Meio Ambiente e Desenvolvimento Regional (2019) e graduada em Ciências Biológicas (2018) pelo Instituto Federal de Educação, Ciência e Tecnologia do Ceará - IFCE, campus Acaraú. Atua na área de Meio Ambiente e Educomunicação. Orcid: https://orcid.org/0000-0001-5081-4852

2 Mestrando em Geografia pela Universidade Estadual do Vale do Acaraú (UVA), especialista em Meio Ambiente e Desenvolvimento Regional (2019) e graduado em Ciências Biológicas (2017) pelo Instituto Federal de Educação, Ciência e Tecnologia do Ceará - IFCE, campus Acaraú. Orcid: https://orcid.org/0000-0002-5295-2455
}

Rev. Nova Paideia -RevistaInterdisciplinaremEducação e PesquisaBrasília/DF, v. 2, n. 3. Núm. Esp.. p. 58 - 71 - ANO 2020 ISSN 2674-5976

DOI: $10.36732 /$ riep.v2i3.58 


\section{Introdução}

O cenário atual global evoca discussões acerca de como as sociedades podem agir em situações de crises como a que enfrentamos no momento (Covid-19), de modo responsável e eficaz. Os impactos gerados por essa pandemia podem ser percebidos tanto na esfera econômica quanto nas esferas política e social dos países ao redor do mundo e mui especialmente no Brasil(LINS RIBEIRO, 2020).

Tais mudanças geraram profundas transformações nos ambientes escolares e no modus operandi de fazer educação no país. De uma hora para outra, muitas instituições de ensino se viram obrigadas a adotar um novo modelo organizacional, alterando seus procedimentos educacionais e incluindo metodologias de ensino a distância a fim de evitar um déficit maior no ensino de seus alunos (UNICEF, 2020).

Essa alteração da rotina escolar ficou bastante evidente no contexto das escolas públicas, uma vez que o uso de recursos tecnológicos como ferramenta educacional ainda é ínfimo em muitos rincões do Brasil. Nesse sentido, cabem alguns questionamentos que trazem à tona a efervescência deste problema: como está sendo encarada essa nova realidade de ensino a distância pelas escolas cearenses, levando em conta esse contexto pandêmico? Será que todos os professores estão capacitados para utilizar os recursos digitais e ambientes virtuais?

É através dessas indagações que este estudo objetiva investigar as medidas adotadas na educação básica cearense para melhor gerir as ações de enfrentamento ao Covid-19. Nesse sentido, diante da realidade conturbada a qual estamos lidando, é preciso considerar as múltiplas medidas que estão sendo implementadas no ensino básico em virtude da necessidade de amenizar os efeitos do novo coronavírus. Portanto, torna-se fundamental inclinar-se a compreender como as escolas cearenses estão respondendo a essa causa de modo a propiciar o melhor ensino a seus alunos.

\section{Aspectos metodológicos}

Esta pesquisa configura-se como de caráter qualitativo, baseando-se no método descritivo-explicativo que, segundo Gil (2008, p. 41) visa "proporcionar maior familiaridade com o problema, com vistas a torná-lo mais explícito ou a constituir hipóteses".

Reconhecemos a exclusividade que esse momento pandêmico se impõe na realidade brasileira e, apesar da baixa disponibilidade em termos de pesquisa e experimentos nos mais diversos setores da sociedade relacionados ao Covid-19, a metodologia aplicada neste trabalho consiste numa pesquisa bibliográfica, o que permite incluir literatura teórica e empírica, bem como estudos com diferentes abordagens metodológicas (quantitativa e qualitativa), onde estes são analisados sistematicamente e podem ser direcionados à definição de conceitos, identificação de lacunas nas áreas de estudos, revisão de teorias e análise metodológica sobre um determinado tema (SOUZA; SILVA; CARVALHO, 2010).

Rev. Nova Paideia -RevistaInterdisciplinaremEducação e PesquisaBrasília/DF, v. 2, n. 3. Núm. Esp.. p. 58 - 71 - ANO 2020 
Realizou-se uma busca na base de dados da Scielo (Scientific Electronic Library Online) e revistas científicas online da área de Educação e Comunicação, como também em reportagens, notícias e documentos que pautam a Legislação Brasileira no que concerne ao campo da Educação. Foram utilizados, para busca dos artigos, os seguintes descritores e suas combinações nas línguas portuguesa, espanhola e inglesa: "Ensino remoto", "Formação de professores" e "TICs". Os critérios de inclusão definidos foram: artigos publicados em português, inglês e espanhol;artigos na íntegra que retratassem a temática referente à revisão integrativa e artigos publicados e indexados nos últimos dez anos.

\section{0 ensino remoto à luz da pandemia de Covid-19}

A situação vigente em todo país, em decorrência da disseminação do Covid-19, tem gerado inúmeras preocupações no campo da educação (UNICEF, 2020), demandando soluções rápidas que pudessem minimizar e até mesmo reverter - ainda que distante - os efeitos da pandemia no meio escolar, sendo o ensino remoto uma das medidas adotadas pelos estados brasileiros para contornar esse panorama.

Há quem considere que o ensino remoto seja comparado a Educação a Distância (EaD) pelas particularidades e semelhanças que estes apresentam e, apesar de ambos utilizarem as ferramentas tecnológicas e digitais como subsídio fundamental para seu desenvolvimento, é preciso levar em consideração que há um aspecto importante entre eles no que tange ao seu emprego: enquanto as aulas remotas são tidas como soluções rápidas e emergenciais para lidar com determinado problema em resposta ao ensino, a modalidade EaD diferencia-se, partindo de um planejamento mais elaborado e sistematizado, com o intuito de favorecer a aprendizagem do aluno através das ferramentas digitais.

Tal providência ainda aparece no contexto das escolas como uma ideia embrionária, mas que se aproveita do progresso e da extensão que os recursos tecnológicos e midiáticos conquistaram nos últimos tempos em nossa sociedade, sendo nítida a mudança drástica no funcionamento do ensino em todo o território nacional, onde em questão de meses, a sala de aula foi trocada pelo espaço de casa e o quadro pela tela de computador ou celular, uma vez que a necessidade volta-se para 0 distanciamento social (INSTITUTO PENÍNSULA, 2020).

No que se concerne às regulamentações dos documentos oficiais acerca das medidas de adoção das aulas remotas, a Lei das Diretrizes e Bases da Educação Nacional (LDB - 9.394/96), por intermédio de seus Art. 32ํ e 36으, deixa claro ao longo de sua construção que a modalidade de Ensino a Distância pode ser recorrida pela educação básica, através da autorização das secretarias de educação e seus respectivos conselhos estaduais e municipais em situações emergenciais e em caráter complementar (BRASIL, 1996).

Essa recomendação foi reforçada posteriormente pelo decreto no 9.057, de 25 de maio de 2017 em seu Art. 8o explicitando que:

Rev. Nova Paideia -RevistaInterdisciplinaremEducação e PesquisaBrasília/DF, v. 2, n. 3. Núm. Esp.. p. 58 - 71 - ANO 2020 


\begin{abstract}
Compete às autoridades dos sistemas de ensino estaduais, municipais e distrital, no âmbito da unidade federativa, autorizar os cursos e o funcionamento de instituições de educação na modalidade a distância nos seguintes níveis e modalidades:
\end{abstract}

I - ensino fundamental, nos termos do $§ 4^{\circ}$ do art. 32 da Lei $\mathrm{n}^{\circ}$ 9.394, de 20 de dezembro de 1996

ensino médio, nos termos do $§ 11^{\circ}$ do art. 36 da Lei no 9.394, de 1996;III educação profissional técnica de nível médio; IV - educação de jovens e adultos; e $\quad$ V - educação especial (BRASIL, 2017).

Certamente, confronta-se a realidade das transformações do meio escolar em virtude dessas ocorrências, em que as escolas precisam adaptar toda sua base de ensino, de modo a tanto atender os alunos em sua totalidade quanto promover uma educação de qualidade a eles. Ocorre também o consentimento das limitações do ensino remoto, ainda mais quando este emerge em um momento conturbado, onde se prejudica, por inúmeros fatores, a sua construção e adequação aos propósitos da escola.

Inclinamo-nos a alegar que adotar o modo de aulas remotas em um cenário amplo e diverso, repleto de intempéries socioeducativas é uma tentativa receosa, mas precisa, nas tomadas de decisão dos órgãos majoritários da educação. Há de se levar em conta fundamentalmente nesse processo, a realidade do ensino no Brasil e principalmente em regiões mais desfavorecidas quando se trata de tecnologia e ensino. Embora os recursos tecnológicos estejam disponíveis na atualidade em praticamente todos os lugares, com relativo impacto, é preciso reconhecer que sua acessibilidade ainda é conflitante.

\title{
4. Formação docente e o desafio da implementação das TICs no ensino básico: desdobramentos decorrentes da realidade educacional
}

A contemporaneidade é marcada por transformações e inovações. Nas últimas décadas foi possível perceber um boom exponencial no desenvolvimento e aperfeiçoamento de produtos tecnológicos e serviços digitais, ofertados e estrategicamente "desenhados" para todos os níveis sociais. 0 acesso à internet e a velocidade com que os meios de comunicação atingem seu público-alvo possibilitaram um alcance maior à informação e um aumento considerável no consumo de conteúdos digitais, principalmente aqueles disseminados no nicho das redes sociais.

Em virtude da globalização, os meios de comunicação como rádio, TV, Internet e outras mídias digitais, passaram a ser cada vez mais presentes no cotidiano das pessoas, alterando o modo como o ser humano interage com o meio social que convive, estabelecendo uma relação de dependência entre o indivíduo e a informação gerada nos ambientes virtuais (CARNIELLO; MOTA, 2017). No contexto escolar esse aspecto é nitidamente visível, o corpo discente é composto de nativos digitais, os estudantes estão habituados com a tecnologia e demonstram mais habilidades no manuseio dessas ferramentas do que os próprios professores. Esse conflito de gerações implica na busca de soluções para melhor aproveitar os recursos existentes e potencializar o ensinoaprendizagem.

Rev. Nova Paideia -RevistaInterdisciplinaremEducação e PesquisaBrasília/DF, v. 2, n. 3. Núm. Esp.. p. 58 - 71 - ANO 2020 
As gerações mudam rapidamente de um período para o outro e, portanto, já não se pode mais pensar num modelo educacional adotado desde o século passado como o método ideal para a educação do século presente. Tendo em vista esse panorama, cabe aos educadores a busca por aperfeiçoamento e desenvolvimento de habilidades no tocante ao uso da tecnologia em sala de aula (SANDIA SALDIVIA;LUZARDO BRICENO; AGUILAR-JIMENEZ, 2019). Os docentes exercem um papel essencial na inserção e utilização dos recursos tecnológicos durante as aulas, sendo mediadores do processo de aprendizagem devem tomar a tecnologia como um meio para conduzir a informação e despertar nos discentes a curiosidade e a criticidade dos conteúdos diante do mar de informações lançadas a todo momento (VARELA-ORDORICA; VALENZUELA-GONZALEZ, 2020).

O uso das mídias no processo educacional não pode ser percebido apenas como complemento do ensino formal e presencial, mas como processo mediador na construção de novos sentidos para a escola e para o docente (ANNIBAL; LUVIZOTTO; ALANIZ, 2017). No âmbito escolar, a inserção dos meios de comunicação de massa induz a um ambiente propício a experimentação e de formação cultural da sociedade (MATEUS; QUIROZ, 2017).

Por conseguinte, inserir ferramentas digitais no ambiente escolar requer domínio tecnológico e maturidade na adoção da tecnologia pela escola. Baseado no estudo TIC transformando a Educação (ICT Transforming Education) da UNESCO, o Centro de Inovação para a Educação Brasileira (CIEB), relata que os níveis de maturidade podem ser classificados de acordo com os elementos apresentados na Figura 1.

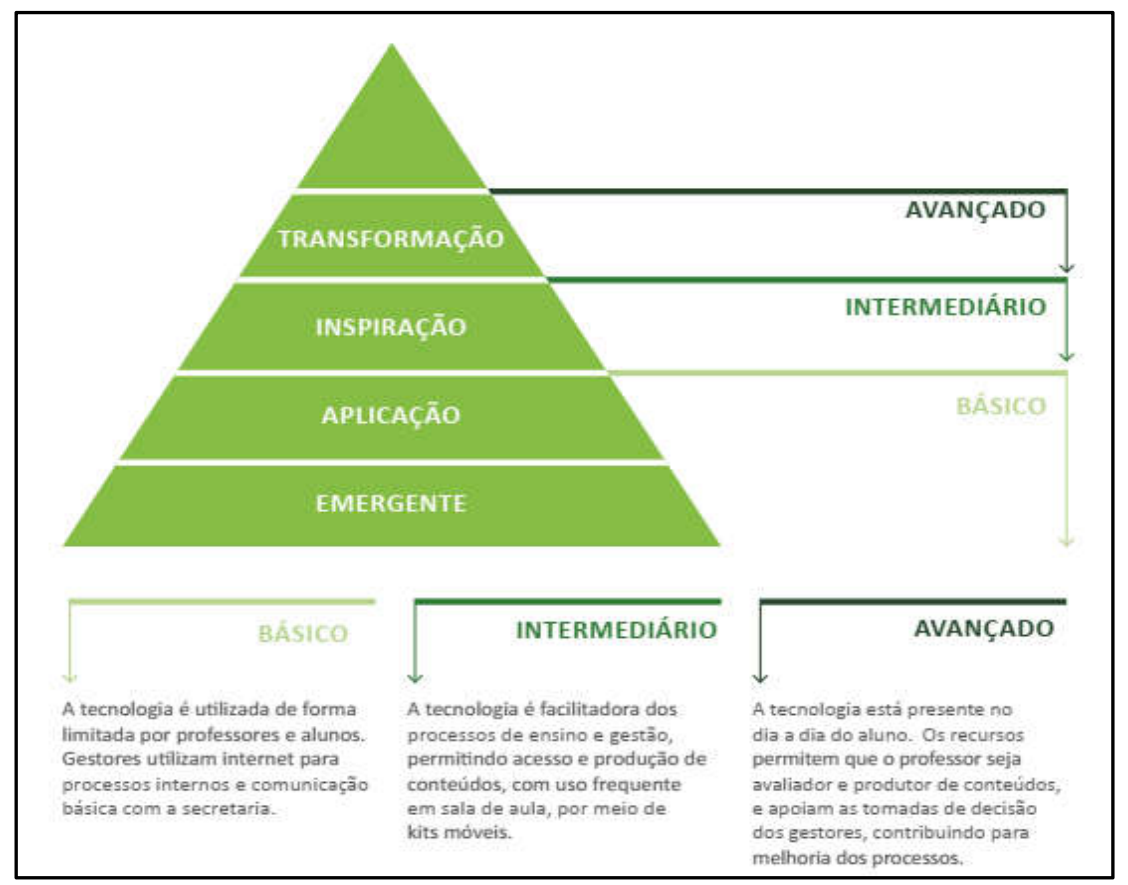

Figura 1 - Níveis de maturidade na adoção de tecnologia. Fonte: CIEB, 2018.

Rev. Nova Paideia -RevistaInterdisciplinaremEducação e PesquisaBrasília/DF, v. 2, n. 3. Núm. Esp.. p. 58 - 71 - ANO 2020 ISSN 2674-5976

DOI: $10.36732 /$ riep.v2i3.58 
Entende-se por TICs (Tecnologias da Informação e Comunicação), a aquisição, o armazenamento, o processamento e a distribuição da informação por meio de dispositivos eletrônicos e digitais. Estabelecendo uma relação com os níveis destacados pelo CIEB, em linhas gerais subtende-se que as escolas públicas brasileiras enfrentam maiores obstáculos na implementação das TICs devido a vários fatores (infraestrutura inadequada, falta de capacitação dos professores, resistência por parte de alguns profissionais em aderir as tecnologias, dentre outros aspectos). No entanto, é importante ressaltar que a realidade das salas de aulas no país é muito distinta.

De acordo com a pesquisa TIC Educação realizada a nível nacional pelo CETIC (Centro Regional de Estudos para o Desenvolvimento da Sociedade da Informação) no ano de 2018, no tocante as fontes de aprendizado sobre tecnologias, $86 \%$ dos professores das escolas privadas e $92 \%$ dos professores das escolas públicas afirmaram buscar por conta própria o conhecimento acerca de recursos digitais. 0 aprendizado a partir de vídeos e tutoriais online passou de 59\% em 2015 para 75\% em 2018, percentuais semelhantes entre professores que lecionam em escolas públicas e particulares.

Dados do CETIC (2018) informam que: 52\% dos responsáveis por escolas rurais afirmam que os professores levam o próprio dispositivo para desenvolver atividades com os alunos, 34\% das escolas possuem ao menos um computador com acesso à internet, $43 \%$ das escolas rurais não possuem acesso à internet por falta de infraestrutura na região onde a instituição se localiza e $24 \%$ pelo alto custo da conexão. Enquanto que em zonas urbanas o índice das escolas que possuem ao menos um computador com acesso à internet chega a $98 \%$.

Obviamente que a discussão acerca das relações entre Educação e Mídias para a formação de professores é longa e permeia diversos campos, como por exemplo: políticas públicas, Ministério da Educação, opinião dos especialistas em educação, membros da sociedade civil, dentre outros setores, que de fato compreendam a necessidade e a importância do processo de formação continuada para a práxis pedagógica.

Vale ressaltar que o docente comprometido com sua prática pedagógica e que está atento as transformações digitais (independentemente da região onde mora),busca investir em formação,aprender sobre novas ferramentas pedagógicas, inovações científicas e tantos outros artifícios para dinamizar e facilitar o processo de ensinoaprendizagem.

Se antes da eclosão do Covid-19, o desafio de implementar a tecnologia na Educação Básica nas escolas públicas a serviço do desenvolvimento estudantil era quase impossível de acontecer ou por que não dizer praticamente nulo, no cenário atual percebeu-se uma abrupta adequação aos recursos digitais.

Rev. Nova Paideia -RevistaInterdisciplinaremEducação e PesquisaBrasília/DF, v. 2, n. 3. Núm. Esp.. p. 58 - 71 - ANO 2020 
O "novo normal" passou a exigir das Secretarias de Educação dos estados brasileiros bem como do MEC, estratégias para minimizar o efeito da pandemia no contexto escolar. Essas medidas mitigatórias suscitam debates e precisam ser realizados maiores estudos sobre o grau de efetividade e de aceitabilidade dessas ações, a fim de melhor compreender os efeitos positivos e negativos do ensino remoto, especialmente nas séries iniciais do Ensino Fundamental.

\section{Implicações na região Nordeste: um olhar para a educação cearense}

Na região Nordeste, um dos obstáculos para o sucesso da implementação das TICs em sua totalidade é a infraestrutura das escolas. É notório a precariedade dos laboratórios de informática (falta computadores para todos os alunos e/ou na maioria das vezes a escola não dispõe desse ambiente), além de que o acesso à internet é limitado ao corpo docente, impossibilitando a devida inclusão no mundo digital.

Com a prorrogação da suspensão das aulas durante a pandemia no estado do Ceará, a SEDUC (Secretaria da Educação do estado do Ceará), orientou as escolas a adotarem o ensino remoto, todavia, a ação por mais bem intencionada que seja abre margem para questionamentos. A acessibilidade é um dos pontos preocupantes,principalmente para os estudantes da rede pública.

Porém, no levantamento realizado pelo SPAECE (Sistema Permanente de Avaliação da Educação Básica do Ceará) em 2018, a maioria dos estudantes informou ter acesso à internet $(73,1 \%)$, o que pode viabilizar as escolas o desenvolvimento de projetos pedagógicos utilizando as novas tecnologias de informação e comunicação. Ainda de acordo com a pesquisa, ter um quarto próprio em casa (relatado por 50,3\% dos estudantes) pode indicar a disponibilidade de um espaço adequado para estudos em casa. Outro aspecto socioeconômico abordado neste estudo foi com relação ao uso de computadores, $65,8 \%$ afirmaram não possuir computador, enquanto que 29,5\% possuem pelo menos um exemplar e $4,8 \%$ possuem dois ou mais computadores. Com relação ao uso de smartphones, $56,1 \%$ afirmaram possuir dois ou mais exemplares, $26,4 \%$ possuem um smartphone e $17,4 \%$ nenhum exemplar.

Diante desse cenário, o Conselho Nacional de Educação (CNE) em colaboração com o Ministério da Educação, aprovou no dia 28 de abril do respectivo ano, as diretrizes para orientar escolas da educação básica e instituições de ensino superior durante a pandemia do coronavírus. 0 material aprovado pelo CNE tem o objetivo de orientar estados, municípios e escolas sobre as práticas que devem ser adotadas durante a pandemia, além de propor normas nacionais gerais.As pautas mais importantes debatidas no encontro virtual foram o calendário escolar de 2020 e se as aulas e as atividades a distância contarão como horas letivas ou terão de ser integralmente repostas quando as aulas presenciais forem retomadas.

De acordo com a SEDUC, um total de oito diretrizes deve guiar as escolas para a elaboração do Plano de Atividades Domiciliares. Cada unidade escolar criou um plano de ensino, com atividades domiciliares para cumprir a carga horária obrigatória de 800

Rev. Nova Paideia -RevistaInterdisciplinaremEducação e PesquisaBrasília/DF, v. 2, n. 3. Núm. Esp.. p. 58 - 71 - ANO 2020 
horas. 0 uso do livro didático é apontado como principal ferramenta para as aulas remotas. Além disso, a Secretaria da Educação apoiará estudantes e educadores no uso das ferramentas digitais, as plataformas digitais disponibilizadas são: Aluno Online, Professor Online, Google Classroom, dentre outras.

Vale destacar também o uso do WhatsApp, Facebook e outras mídias sociais, que tem facilitado a entrega dos conteúdos e atividades por meio dos grupos criados nesses veículos de comunicação. Para os alunos que não possuem acesso aos recursos digitais, cada escola ficará responsável por imprimir e entregar o material didático para cada estudante, seguindo as medidas recomendadas pelo Ministério da Saúde.

Entretanto, mesmo com todo o suporte prestado pela SEDUC e secretarias municipais, muitos gestores escolares têm notado que o resultado não tem saído como esperado. A maioria dos alunos não possuem smartphone, vendo-se obrigados a usar emprestado o aparelho dos pais ou de algum parente para receber e encaminhar as atividades. Dentre estes que recebem as atividades via celular, alguns não realizam as tarefas e tampouco enviam justificativa. Outro ponto a ser discutido, é o fato de muitos pais não saber como auxiliar seus filhos na resolução das questões, o que dificulta mais ainda o processo de aprendizagem dos estudantes. 0 que esperar dessa estratégia? Como proceder diante dessa problemática?

Especialistas em educação afirmam que adotar o modelo de Educação a Distância no ensino básico não é a melhor alternativa para um ensino de qualidade, principalmente no que concerne a rede pública de ensino, onde há uma diversidade de realidades e contextos sociais (HAYASHI et al., 2020).

A pesquisa, ainda em andamento, intitulada "Sentimento e percepção dos professores brasileiros nos diferentes estágios do Coronavírus no Brasil”, recentemente lançada pelo Instituto Península, realizada entre os dias 13 de abril e 14 de maio de 2020 com 7.734 mil professores de todo o país, revelou que $83,4 \%$ dos professores não se sentem preparados para o ensino remoto e mesmo aqueles com experiência e robusta formação em tecnologias e ensino a distância foram pegos de surpresa, 88\% deles afirmaram que nunca tinham dado aula virtual antes da pandemia. 0 respectivo relatório inclui também informações sobre infraestrutura, apoio emocional dos profissionais da educação, dentre outros aspectos intrínsecos ao presente momento

Essa preocupação surge do fato de que embora o ensino remoto seja uma alternativa ao distanciamento temporário, evidentemente algumas lacunas serão criadas e consequentemente afetará no desempenho dos estudantes. Ainda de acordo com os dados divulgados pelo Instituto Península, mesmo com todos os desafios do ensino remoto, $75 \%$ dos professores gostariam de receber apoio e treinamento para atuar nos ambientes virtuais, seguido de apoio pedagógico para auxiliar os alunos (64\%) e apoio psicológico/emocional (55\%). Todavia, o que se pode esperar daqui pra frente é a continuação da adoção dos recursos digitais no dia a dia escolar, uma adaptação ao modelo de ensino híbrido.

Rev. Nova Paideia -RevistaInterdisciplinaremEducação e PesquisaBrasília/DF, v. 2, n. 3. Núm. Esp.. p. 58 - 71 - ANO 2020 


\section{Reflexos da influência do COVID-19 e da adesão das TICs nas escolas cearenses}

A implementação das mídias virtuais como ferramentas de elo para a promoção do processo de ensino-aprendizagem trouxe consigo uma gama de possibilidades que permitiram com que as aulas fossem retomadas ao longo do contexto pandêmico, mas vale ressaltar que, embora seja possível a execução de atividades através dessas plataformas digitais, é preciso considerar a qualidade de ensino ofertado, principalmente quando colocado em pauta a aderência dessa possibilidade de ensinar aos alunos.

Uma das soluções tomadas nas escolas cearenses consiste no encaminhamento das aulas para os alunos através das mídias sociais tão amplamente conhecidas e utilizadas por eles (Whatsapp, Facebook e outras). As tarefas são postadas e consequentemente o retorno delas é feito nesse ambiente, sendo possível não somente a comunicação dos alunos com o professor e vice-versa, mas também dos próprios alunos entre si e o engajamento da família. Essa solução aparece como uma esperança para o ensino e o contato dos alunos com a escola, mas que se manifesta de maneira inesperada conforme sua utilização.

Sabemos dos inúmeros fatores que permeiam a realidade do ensino tanto presencial quanto das aulas remotas e do forte impacto que eles têm na dinâmica escolar (OLIVEIRA; SCHWARTZMAN, 2002), o que acarreta a necessidade de se repensar o currículo e adequá-lo à realidade a qual estamos passando, considerando os alunos, os professores e demais funcionários envolvidos. Esse planejamento requer tempo e o comprometimento dos atores que fazem parte da escola é fundamental na tentativa de buscar medidas mitigatórias para que o ensino seja ofertado aos alunos com mais consistência (MORAN, 2007). Entretanto, pode-se perceber que essa adoção de estratégias diversificadas se deu em um momento em que a escola não estava preparada para essa adequação e muito menos inclinada a incluir o planejamento dessa nova forma de ensinar voltada para essa perspectiva.

Os efeitos desse novo panorama são notórios e perpassam pelos vários sujeitos envolvidos na educação: (1) professores, que precisam se desdobrar para planejar e desenvolver os conteúdos de maneira eficaz e significativa aos alunos, além de manter a interatividade e o interesse destes e outras funções; (2) gestores, que necessitam compreender e realocar a escola para essa nova proposição frente às dificuldades e necessidades da sociedade; (3) órgãos credenciados e responsáveis pelo ordenamento e pelas políticas públicas educacionais em consonância com a realidade; (4) alunos, que precisam refletir sobre suas atribuições e atitudes diante desses efeitos; (5) famílias, que precisam adentrar nesse processo com uma postura mais colaborativa com a escola.

De todo modo, precisamos voltar o olhar para a robustez das implicações que surgem nessa tentativa de ofertar o conhecimento nesse estilo e no presente cenário. Promover aulas através de plataformas virtuais como meio de se sobressair da pandemia de coronavírus não tornará este ensino com qualidade, mas planejar visando

Rev. Nova Paideia -RevistaInterdisciplinaremEducação e PesquisaBrasília/DF, v. 2, n. 3. Núm. Esp.. p. 58 - 71 - ANO 2020 
a aprendizagem e a participação dos alunos ao invés de lhes atribuir um amontoado de tarefas diárias para camuflar o despreparo das instituições escolares, é uma possível estratégia.

Nesse sentido, é importante destacar que:

[...] o ato de planejar exige aspectos básicos a serem considerados. Um primeiro aspecto é o conhecimento da realidade daquilo que se deseja planejar, quais as principais necessidades que precisam ser trabalhadas; para que o planejador as evidencie faz-se necessário fazer primeiro um trabalho de sondagem da realidade daquilo que ele pretende planejar, para assim, traçar finalidades, metas ou objetivos daquilo que está mais urgente de se trabalhar (OLIVEIRA, 2007, p. 21).

É fato que não podemos deixar de incluir como tangente fundamental desse processo o próprio Covid-19 e suas implicações diretas com todos os setores, o que obriga de certa forma a esse novo enquadramento para a manutenção da sociedade, contudo, a escola ainda se encontra desajustada em face dessa problemática atual - e não seria diferente - o que fortemente nos proporciona uma reflexão acerca de como é complexo o processo de ensinar e de pensar Educação diante dessas recentes transformações.

Reforçamos a validade das mídias digitais como fortalecedoras e aliadas da escola não somente nesse contexto, mas de forma generalizada, sobretudo, no que diz respeito ao potencial que elas têm de atingir os alunos e tornar fluido o ensino e a aprendizagem. No entanto, ressaltamos que a verdadeira atenção se alicerça sobre os professores e gestores no encaminhamento e na modelação dessas mídias para atingir os objetivos e propósitos do ensino.

Reconhecemos, também, a necessidade de um engajamento no planejamento escolar com a finalidade de estabelecer métodos diferenciados que visem a integração do aluno com o ensino, uma vez que, em tempos atuais, a busca por respostas prontas no ambiente virtual é imensa, o que proporciona certa fragilidade na efetividade dessas práticas. Ademais, é preciso ainda que os alunos sejam instigados a obter o conhecimento e a refletir sobre seu papel na sociedade, atribuindo-lhes criticidade e capacidade de pensar e agir frente às problemáticas ao redor.

É verídico afirmar que, por um lado, tais transformações e adaptações da escola para lidar com a realidade do coronavírus e a promoção do ensino é uma tarefa extremamente complexa e exaustiva, devendo considerar muitos aspectos como a gestão, o preparo dos professores para o enfrentamento dessas circunstâncias, a adequação das mídias virtuais como potencializadoras do conhecimento e não como meros veículos de envio de trabalhos e correções, e a reflexão de que, mesmo à distância, o ensino precisa ser promovido aos alunos de maneira a prepará-los para atuar em sociedade. Por outro lado, há de se considerar que a escola precisa estar em sintonia com os alunos e as famílias, o que em nossa concepção se configura como um dos

Rev. Nova Paideia -RevistaInterdisciplinaremEducação e PesquisaBrasília/DF, v. 2, n. 3. Núm. Esp.. p. 58 - 71 - ANO 2020 ISSN 2674-5976

DOI: $10.36732 /$ riep.v2i3.58 
grandes desafios desse recente embate, onde a comunicação é essencial para manter essa relação, principalmente levando em consideração que nem todas as famílias têm acesso e conhecimento acerca do manuseio das mídias digitais, deixando que muitos alunos estejam por conta própria nesse processo.

Através dessas repercussões em que o quadro pandêmico assenta-se sobre a educação, colocamo-nos em constante reflexão para entender o quanto que a escola precisa rever e munir-se de estratégias para contornar essa causa e, ainda mais, estabelecer medidas e parcerias junto às famílias, sendo todos esses passos marcados pelo avanço do tempo e dos efeitos do Covid-19.

\section{Considerações finais}

Esse estudo possibilitou compreender como a Educação está enfrentando a crise de pandemia do coronavírus e refletir acerca das medidas que estão sendo empregadas em um período de muitas restrições e de distanciamento social na tentativa de oferecer mais qualidade ao ensino básico do país.

Verificou-se que a solução adotada de imediato pelas escolas cearenses para continuar promovendo o ensino a seus alunos deu-se através das mídias virtuais, sendo utilizadas para o envio e recebimento de atividades, correções e trocas de informação dentro de tais veículos. Porém, isso não garante que a aprendizagem esteja sendo alcançada, nem mesmo verificar com que qualidade esse ensino está sendo promovido.Atrelado a esse fator, ainda existe a questão da formação e do aperfeiçoamento docente para o ambiente virtual e o manuseio dos recursos tecnológicos da comunicação, o que contribui significativamente no modo como o professor pode ou não utilizar a seu favor essas ferramentas.

A partir dessas análises, pode-se perceber que ainda há muito o que avançar no quesito formação docente, principalmente no que diz respeito as novas tecnologias na educação, visto que muitos professores não sabem como utilizar tais ferramentas e nem para que finalidades devem inseri-las em sua prática, o que nos deixa preocupados no caminhar do ensino nesse momento pandêmico.

Além disso, apesar da "obrigatoriedade" do uso das tecnologias como soluções estratégicas para atenuar o déficit educacional e suas implicações nos diversos contextos regionais, cabe ressaltar aqui que a realidade é o reflexo do descaso que se enraíza no cenário brasileiro em que muitos estudantes não possuem acesso aos recursos tecnológicos, e por vezes, quando tem acesso, utilizam-nos de forma restritiva, seja pela baixa conexão com a internet ou pela limitação dos equipamentos, fatores esses que são inibidores da aprendizagem a distância.

Considerar a aceitação das aulas remotas como método de ensino impulsionado pela pandemia do Covid-19 implica levar em conta que esse método esteja disponível a todos e, mais ainda, seja acessível para que o processo de ensino e aprendizagem ocorra satisfatoriamente.É factual que somente o estabelecimento dessa relação alunotecnologia-escola em tempos de pandemia não é suficiente para atingir os objetivos de uma educação de qualidade, mas que quando realizada de modo planejado e integrado,

Rev. Nova Paideia -RevistaInterdisciplinaremEducação e PesquisaBrasília/DF, v. 2, n. 3. Núm. Esp.. p. 58 - 71 - ANO 2020 
ameniza a dimensão dos efeitos sobre o ensino em uma perspectiva de manter a relação entre o aluno e a escola.

Paulo Freire, um dos grandes pensadores da educação, no livro Pedagogia da Autonomia afirmava que: "ensinar não é transferir conhecimento, mas criar as possibilidades para a sua própria produção ou a sua construção". Tal afirmação, reverberou com mais consonância nesse período, pois mediante situações inesperadas, o reinventar-se e o adaptar-se, foram elementos essenciais para minimizar o dano gerado pela pandemia no contexto educacional.

Nesse sentido, percebe-se que embora seja uma tentativa de garantir que os alunos continuem estudando, irradia-se através dessa decisão um emaranhado de fatores que intervêm e perpassam nesse processo, fatores estes que giram em torno da adequação das aulas, formação profissional e principalmente motivação para o enfrentamento dessa realidade. É essencial olhar o debruçar da educação frente a essa onda de conflitos e inseguranças que se intercalam com soberania sobre as instituições de ensino, gerando adaptações e medidas para encontrar soluções cada vez mais coerentes - o que não é fácil -, mas que se atribui a um dos papéis da escola, a busca de alternativas para a promoção da educação.

\section{Referências}

ANNIBAL, Sérgio Fabiano; LUVIZOTTO, Caroline Kraus; ALANIZ, Érika Porceli. Mídiaeducação, educomunicação e formação de professores. Revista Latinoamericana de Ciencias de la Comunicación, v. 14, n. 26, 2017. Disponível em:

<https://bit.ly/37UCmgP>. Acesso em: 02 jun. 2020.

BRASIL. Lei de Diretrizes e Bases da Educação Nacional. Lei no 9.394/96, de 20 de dezembro de 1996. Disponível em: <https://bit.ly/31bbS9Q>. Acesso em: 02 jun. 2020.

BRASIL. Decreto № 9.057, de 25 de maio de 2017. Regulamenta o art. 80 da Lei no 9.394, de 20 de dezembro de 1996, que estabelece as diretrizes e bases da educação nacional. Brasília, DF, 2017. Disponível em: < https://bit.ly/2VaZbYF $>$. Acesso em 01 jun. 2020.

CARNIELLO, Monica Franchi; MOTA, Hugo Análio. Educomunicação: um estudo das práticas nas salas de aula. REU, Sorocaba, SP, v. 43, n. 2, p. 351 - 371, dez. 2017. Disponível em: <https://bit.ly/3dqGari>. Acesso em: 02 jun. 2020.

CENTRO REGIONAL DE ESTUDOS PARA O DESENVOLVIMENTO DA SOCIEDADE DA INFORMAÇÃO (CETIC). Tic Educação 2018. Coletiva de Imprensa. São Paulo, 16 julho de 2019. Disponível em: <https://bit.ly/3hWLkz1>. Acesso em: 02 jun. 2020.

CENTRO DE INOVAÇÃO PARA A EDUCAÇÃO BRASILEIRA (CIEB). Notas técnicas: níveis de maturidade de adoção de tecnologia pela escola. 2018. Disponível em:

$<$ https://bit.ly/2VaZyCx>. Acesso em: 02 jun. 2020.

Rev. Nova Paideia -RevistaInterdisciplinaremEducação e PesquisaBrasília/DF, v. 2, n. 3. Núm. Esp.. p. 58 - 71 - ANO 2020 
FREIRE, Paulo Pedagogia da autonomia: saberes necessários a prática educativa. São Paulo: Paz e Terra, 2004.

GIL, A. C. Como elaborar projetos de pesquisa. 5. ed. São Paulo: Atlas, 2008.

HAYASHI, Carmino; SOEIRA, Fernando dos Santos; CUSTÓDIO, Fernanda Rodrigues. Analysis of Public Policies in Distance Education in Brazil. Research, Society and Development, Itabira, v. 9, n. 1, p. e87911667, jan. 2020. Disponível em :< https://bit.ly/3dtKohQ>. Acesso em: 07 jun. 2020.

INSTITUTO PENÍNSULA. Sentimento e percepção dos professores brasileiros nos diferentes estágios do Coronavírus no Brasil.2020. Disponível em: $<$ https://bit.ly/385TlgB $>$. Acesso em: 10 jun. 2020.

LINS RIBEIRO, G. Medo Global. Boletim Ciências Sociais: Cientistas Sociais e o Coronavírus. Boletim Especial n. 5, ANPOCS, 26/03/2020. Disponível em: $<$ https://bit.ly/2YsFy0o $>$. Acesso em: 10 jun. 2020.

MATEUS, Julio César; QUIROZ, Maria Teresa. Educommunication: a theoretical approach of studying media in school environments. Revista Latinoamericana de Ciencias de la Comunicación, v. 14, n. 26, 2017. Disponível em:

$<$ https://bit.ly/2B5SyA3>. Acesso em: 02 jun. 2020.

OLIVEIRA, D. de A. Gestão democrática da educação: desafios contemporâneos. 7̣a ed. Petrópolis, RJ: Ed. Vozes, 2007.

OLIVEIRA, J. B. A.; SCHWARTZMAN, S. A escola vista por dentro. Belo Horizonte: Alfa Educativa, 2002.

SANDIA SALDIVIA, Beatriz Elena; LUZARDO BRICENO, Marianela; AGUILAR-JIMENEZ, Alba Soraya. Apropiación de las Tecnologías de Información y Comunicación como Generadoras de Innovaciones Educativas.Cienc. docencia tecnol., Concepción del Uruguay, n. 58, p. 267-289, mayo 2019. Disponível em: <https://bit.ly/3etT619>>. Acesso em: 21 jun. 2020.

SECRETARIA DA EDUCAÇÃO DO ESTADO DO CEARÁ (SEDUC). SPAECE - 2018. Conteúdo: Sumário Executivo. Universidade Federal de Juiz de Fora, Faculdade de Educação, CAEd. V. 7 (jan./dez. 2018), Juiz de Fora, 2018 - Anual. ISSN 1982-7644. Disponível em: <https://bit.ly/3et]N1c>. Acesso em: 04 jun. 2020.

SECRETARIA DA EDUCAÇÃO DO ESTADO DO CEARÁ (SEDUC). Guia de estudos domiciliares. 2020. Disponível em: <https://bit.ly/2V9Ixsv>. Acesso em: 03 jun. 2020.

SOUZA, Marcela Tavares; SILVA Michelly Dias; CARVALHO, Rachel de. Revisão integrativa: o que é e como fazer. Einstein, 2010; 8 (Supl. 1):102-106. Disponível em: $<$ https://bit.ly/2YqQonf $>$. Acesso em: 21 jun. 2020. 
UNICEF (2020). Covid-19: Mais de 95\% das crianças estão fora da escola na América

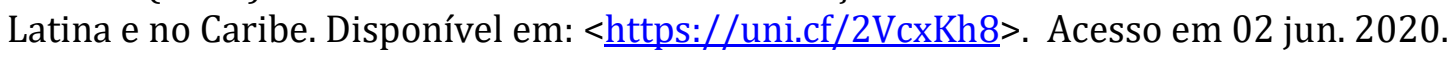

VARELA-ORDORICA, Sandra Araceli; VALENZUELA-GONZALEZ, Jaime Ricardo. Uso de las tecnologías de la información y la comunicación como competencia transversal en la formación inicial de docentes. Educare, Heredia , v. 24, n. 1, p. 172-191, abr. 2020. Disponível em: <https://bit.ly/37VHrpt>. Acesso em: 21 jun. 2020. 